\title{
Zygapophyseal Joint Orientation and Facet Tropism and Their Association with Lumbar Disc Prolapse
}

\author{
Tarush Rustagi $^{1,2}$, Harvinder Singh Chhabra ${ }^{1}$, Kalidutta Das ${ }^{1}$ \\ ${ }^{1}$ Department of Spine Surgery, Indian Spinal Injuries Centre, New Delhi, India \\ ${ }^{2}$ Ohio State University and Wexner Medical Center, Columbus, OH, USA
}

Dear Editor,

We read with great interest the article by Mohanty et al. [1] titled "Zygapophyseal joint orientation and facet tropism and their association with lumbar disc prolapse." The authors have done a commendable job in identifying the association between facet tropism and disc degeneration in an Indian population. Although previous studies have both supported and refuted this concept, the effect of facet orientation cannot be neglected and warrants discussion.

In their introduction, the authors have defined facet tropism as $>7^{\circ}$ in reference to the study by Vanharanta et al. [2] in 1993. Care should be taken when using this value in interpreting the data. Vanharanta et al. [2] in 1993 found that most cases had $\leq 7^{\circ}$ in the variation of the facet angle difference when disc degeneration was not observed. Similarly, other authors have determined this value to be of different magnitudes based on their respective asymptomatic cohorts, ranging from $5^{\circ}$ to $10^{\circ}$ [3-5]. Therefore, the value of tropism is not standard and varies with specific data being interpreted. Although it may be appropriate to consider a standard value derived from another study, one should account for morphometric differences between populations. The authors in a previous study on facet tropism in the south Indian population concluded that val- ues differ from those of the Western literature; however, they did not examine any asymptomatic population [6].

While this study adds value to the existing literature, it is also important to identify standard values based on region-based Indian populations because facet angle values are influenced by race and ethnicity.

\section{Conflict of Interest}

No potential conflict of interest relevant to this article was reported.

\section{References}

1. Mohanty SP, Kanhangad MP, Kamath S, Kamath A. Zygapophyseal joint orientation and facet tropism and their association with lumbar disc prolapse. Asian Spine J 2018;12:902-9.

2. Vanharanta H, Floyd T, Ohnmeiss DD, Hochschuler $\mathrm{SH}$, Guyer RD. The relationship of facet tropism to degenerative disc disease. Spine (Phila Pa 1976) 1993;18:1000-5.

3. Noren R, Trafimow J, Andersson GB, Huckman MS. The role of facet joint tropism and facet angle in disc degeneration. Spine (Phila Pa 1976) 1991;16:530-2.

Received Oct 12, 2018; Accepted Oct 15, 2018

Corresponding author: Tarush Rustagi

Department of Spine Surgery, Indian Spinal Injuries Centre, Vasant Kunj, New Delhi-110070, India

Tel: +91-011-42255225, E-mail: tarush.rustagi@gmail.com 
4. Boden SD, Riew KD, Yamaguchi K, Branch TP, Schellinger D, Wiesel SW. Orientation of the lumbar facet joints: association with degenerative disc disease. J Bone Joint Surg Am 1996;78:403-11.

5. Chadha M, Sharma G, Arora SS, Kochar V. Association of facet tropism with lumbar disc herniation. Eur Spine J 2013;22:1045-52.
6. Mohanty SP, Pai Kanhangad M, Kamath S, Kamath A. Morphometric study of the orientation of lumbar zygapophyseal joints in a South Indian population. J Orthop Surg (Hong Kong) 2017;25:2309499017739483. 